\title{
The maternal immune response to fetal platelet GPIb $\alpha$ causes frequent miscarriage in mice that can be prevented by intravenous IgG and anti-FcRn therapies
}

Conglei Li, ,1,2 Siavash Piran,1,2 Pingguo Chen,2,3 Sean Lang,,1,2,3 Alessandro Zarpellon, ${ }^{4}$ Joseph W. Jin, ${ }^{2,3}$ Guangheng Zhu, ${ }^{2}$ Adili Reheman, ${ }^{2}$ Dianne E. van der Wal, ${ }^{2}$ Elisa K. Simpson, ${ }^{1,2}$ Ran Ni, ${ }^{5}$ Peter L. Gross, ${ }^{5}$ Jerry Ware, ${ }^{6}$ Zaverio M. Ruggeri, ${ }^{4}$ John Freedman, ${ }^{1,2,7}$ and Heyu Ni ${ }^{1,2,3,7,8}$

1Department of Laboratory Medicine and Pathobiology, University of Toronto, Toronto, Ontario, Canada.

${ }^{2}$ Toronto Platelet Immunobiology Group and Department of Laboratory Medicine, Keenan Research Centre in the Li Ka Shing Knowledge Institute of St. Michael's Hospital, Toronto, Ontario, Canada. ${ }^{3}$ Canadian Blood Services, Toronto, Ontario, Canada. 4Department of Molecular and Experimental Medicine, The Scripps Research Institute, La Jolla, California, USA. ${ }^{5}$ Department of Medicine, McMaster University, Hamilton, Ontario, Canada. ${ }^{6}$ Department of Physiology and Biophysics, University of Arkansas for Medical Sciences, Little Rock, Arkansas, USA. ${ }^{7}$ Department of Medicine and ${ }^{8}$ Department of Physiology, University of Toronto, Ontario, Canada.

\begin{abstract}
Fetal and neonatal immune thrombocytopenia (FNIT) is a severe bleeding disorder caused by maternal antibody-mediated destruction of fetal/neonatal platelets. It is the most common cause of severe thrombocytopenia in neonates, but the frequency of FNIT-related miscarriage is unknown, and the mechanism(s) underlying fetal mortality have not been explored. Furthermore, although platelet $\alpha \operatorname{IIb} \beta 3$ integrin and GPIb $\alpha$ are the major antibody targets in immune thrombocytopenia, the reported incidence of anti-GPIb $\alpha$-mediated FNIT is rare. Here, we developed mouse models of FNIT mediated by antibodies specific for GPIb $\alpha$ and $\beta 3$ integrin and compared their pathogenesis. We found, unexpectedly, that miscarriage occurred in the majority of pregnancies in our model of anti-GPIb $\alpha$-mediated FNIT, which was far more frequent than in anti- $\beta 3$-mediated FNIT. Dams with anti-GPIb $\alpha$ antibodies exhibited extensive fibrin deposition and apoptosis/necrosis in their placentas, which severely impaired placental function. Furthermore, anti-GPIb $\alpha$ (but not anti- $\beta 3$ ) antiserum activated platelets and enhanced fibrin formation in vitro and thrombus formation in vivo. Importantly, treatment with either intravenous IgG or a monoclonal antibody specific for the neonatal Fc receptor efficiently prevented anti-GPIb $\alpha$-mediated FNIT. Thus, the maternal immune response to fetal GPIb $\alpha$ causes what we believe to be a previously unidentified, nonclassical FNIT (i.e., spontaneous miscarriage but not neonatal bleeding) in mice. These results suggest that a similar pathology may have masked the severity and frequency of human anti-GPIb $\alpha$-mediated FNIT, but also point to possible therapeutic interventions.
\end{abstract}

\section{Introduction}

Fetal and neonatal immune thrombocytopenia (FNIT) is a severe alloimmune disorder that results from fetal/neonatal platelet destruction by maternal antibodies generated during pregnancy (1-4). FNIT is the most common type of severe thrombocytopenia in live-born neonates and carries a major risk of intracranial hemorrhage, which can lead to neurological impairment or death (5-8). The incidence of FNIT has been estimated at $0.5-1.5$ per 1,000 liveborn neonates (1-4). This number, however, does not include miscarriages caused by the disease, since the rate of fetal mortality in affected pregnant women has not been adequately studied, although miscarriage has been reported by several groups (9-13). Currently, the mechanisms leading to miscarriage in these women and the therapies to prevent this devastating consequence are unknown.

Platelets play a critical role in hemostasis and thrombosis. Platelet adhesion, activation, and aggregation at the site of vascular injury lead to the formation of a platelet plug and the subsequent arrest of bleeding. However, accumulation of activated platelets at inappropriate sites (e.g., atherosclerotic lesions) may lead to thrombus

Conflict of interest: The authors have declared that no conflict of interest exists. Citation for this article: J Clin Invest. 2011;121(11):4537-4547. doi:10.1172/JCI57850. formation and vessel obstruction (14-16). In addition, activated platelets may generate negatively charged phospholipids (e.g., phosphatidylserine [PS]) on their surfaces, which promote thrombin generation and fibrin formation (17-19). This procoagulant activity facilitates hemostasis but may also enhance the severity of thrombotic disorders. To date, there is no report regarding whether thrombosis in the placenta may be involved in the pathogenesis of FNIT and contribute to the miscarriage observed in this disease.

Integrin $\alpha I I b \beta 3$ (GPIIb/IIIa) and the GPIb $\alpha$ complex are major glycoproteins on the platelet surface and are critically required for platelet adhesion and aggregation. In FNIT, most reported cases (75\%-95\%) have been characterized by maternal alloantibodies to fetal $\beta 3$ integrin $(20,21)$, with few reported cases of FNIT associated with anti-GPIb $\alpha$ antibodies $(22-27)$. This is in stark contrast to the $20 \%-40 \%$ prevalence of anti-GPIb $\alpha$ complex antibodies in patients with immune thrombocytopenia (ITP) (28-30), an analogous bleeding disorder in which patients have autoimmune responses to the same platelet antigens as in FNIT ( $\beta 3$ integrin and GPIb $\alpha$ ). The underlying reason for the surprisingly low incidence of FNIT mediated by anti-GPIb $\alpha$ antibodies has not been explored, and the maternal immune responses to fetal platelet antigens remain to be elucidated. 

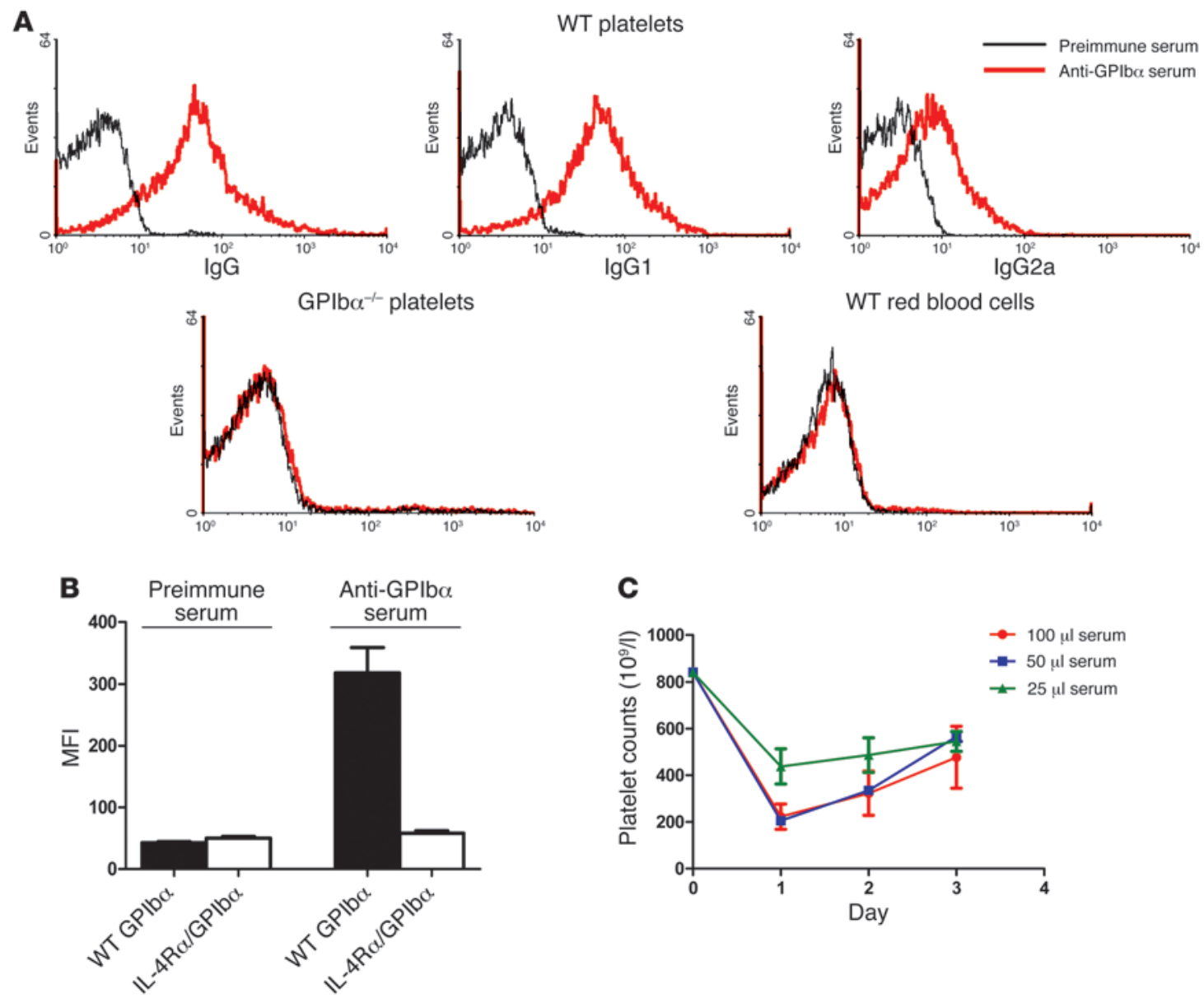

Figure 1

Anti-GPIb $\alpha$ antibodies were generated in $\mathrm{GPIb}^{-/-}$mice after WT platelet transfusions. (A) WT mouse platelets were incubated with a 1:100 dilution of either antiserum from GPIbo- ${ }^{-1-}$ mice immunized twice with $10^{8} \mathrm{WT}$ platelets or preimmune serum and stained with FITC-conjugated anti-mouse IgG, IgG1, or IgG2a. GPIb ${ }^{-/-}$platelets and WT red blood cells were used as negative controls. (B) Anti-GPIb $\alpha$ serum (diluted at 1:250) specifically recognized murine platelets expressing WT GPIb $\alpha$, but not IL-4R $\alpha / G P I b \alpha$, while preimmune serum failed to recognize either. (C) Anti-GPIb $\alpha$ antiserum $(100 \mu \mathrm{l}, 50 \mu \mathrm{l}$, or $25 \mu \mathrm{l})$ was intravenously injected into WT mice, and thrombocytopenia was efficiently induced. Results are representative of 3 independent experiments $(n=3-4$ mice in each group).

In the current study, we developed two murine models of FNIT in syngeneic GPIb $\alpha$-deficient $\left(\mathrm{GPIb}^{-/-}\right)$and $\beta 3$ integrin-deficient $\left(\beta 3^{-/-}\right)$mice. We found that anti-GPIb $\alpha$ caused miscarriage (complete lack of parturition) in most affected mothers and markedly enhanced fibrin deposition in their placentas, leading to impairment in placental function. This is different from FNIT as it is traditionally conceived, as a disorder primarily characterized by bleeding symptoms in neonates. The high incidence of miscarriage likely contributes to the rarity of case reports of anti-GPIb $\alpha$-mediated FNIT. We further demonstrated that intravenous IgG (IVIG) and an $\mathrm{mAb}$ against the neonatal $\mathrm{Fc}$ receptor $(\mathrm{FcRn})$ can prevent this devastating consequence.

\section{Results}

$G P I b \alpha^{-/-}$mice were immunoresponsive to the GPIb $\alpha$ antigen on transfused WT platelets. The reported incidence of human anti-GPIb $\alpha$-mediated FNIT is rare. Little information is available regarding how the maternal immune response to the GPIb $\alpha$ antigen occurs and whether GPIb $\alpha^{-/-}$mice are immunoresponsive to the GPIb $\alpha$ antigen after these antigen-positive platelets enter the blood circulation. Since there was no animal model to address this question, we first tested whether specific anti-GPIb $\alpha$ antibodies can be generated in GPIb $\alpha^{-/-}$ mice and whether these antibodies can induce thrombocytopenia.

To develop a new FNIT model with $\mathrm{GPIb}^{-/-}$mice, in order to compare the pathogenesis with that of anti- $\beta 3$ integrin-mediated FNIT, we first backcrossed GPIb $\alpha^{-/-}$and $\beta 3^{-/-}$mice to a BALB/c background 10 times. The BALB/c GPIb $\alpha^{-/-}$and $\beta 3^{-/-}$strains were further crossed to each other to generate syngeneic gene-deficient mice. To mimic the human preconception exposure to the GPIb $\alpha$ antigen, or human mothers who had previous pregnancies that exposed them to fetal platelet GPIb $\alpha$ (e.g., human platelet antigen 2 [HPA-2]), we transfused GPIb $\alpha^{-/-}$females with WT platelets. We found that $\mathrm{GPIb}^{-/-}$mice mounted a significant immune response to GPIb $\alpha$ after two transfusions of $10^{8}$ gel-filtered WT platelets, and both IgG1 and IgG2a isotype antibodies were detected (Figure 1A), indicative of both Th1- and Th2-like immune responses. The antibodies from immunized GPIb $\alpha^{-/-}$mice were specific to GPIb $\alpha$, as they did not recognize either $\mathrm{GPIba}^{-/}$platelets or WT red blood cells. The 
A

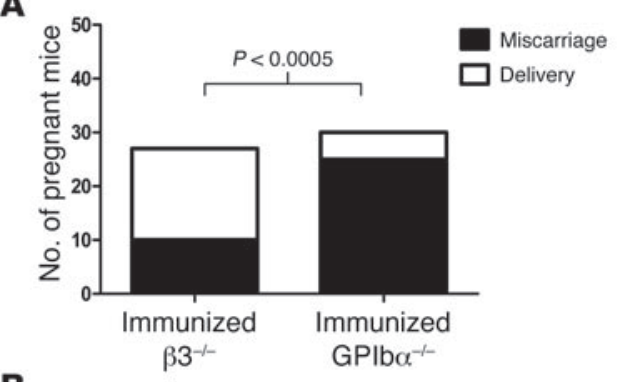

B

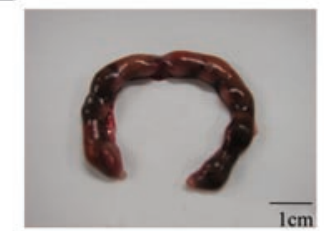

Immunized GPlb $\alpha^{-1-}$

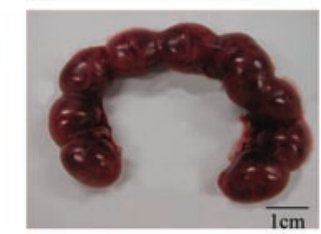

Naive GPIb $\alpha^{-1-}$

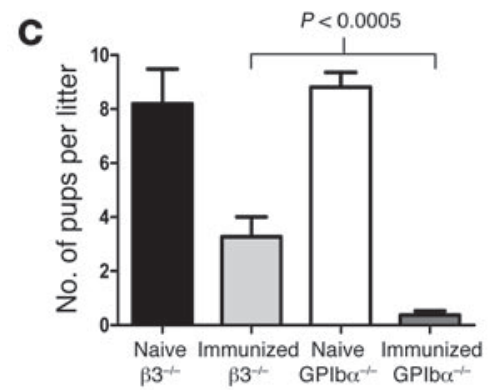

specificity of anti-GPIb $\alpha$ polyclonal antibodies was also confirmed via Western blot analysis using a rat anti-mouse GPIb $\alpha$ mAb (p0p5) (31) as a control. Using murine platelets expressing the IL-4R $\alpha / \mathrm{GPIb}-\mathrm{IX}$ complex, in which most of the extracellular domain of GPIb $\alpha$ is replaced by the $\alpha$-subunit of the human IL- 4 receptor (IL-4R $\alpha$ ) (32), we found that the anti-GPIb $\alpha$ antibodies specifically bound to platelets expressing WT GPIb $\alpha$, but not IL-4R $\alpha /$ GPIb $\alpha$ (Figure 1B). Since the expression levels of $\alpha \mathrm{IIb} \beta 3$ integrin, GPV, and GPIX are normal on the surface of IL-4R $\alpha /$ GPIb $\alpha$ transgenic platelets (33), these anti-GPIb $\alpha$ antibodies do not cross-react with other proteins on platelets, including $\beta 3$ integrins and glycoproteins in the GPIbV-IX complex. Thrombocytopenia was efficiently induced in adult WT mice after injection of the anti-GPIb $\alpha$ antiserum (Figure 1C). These data indicate that $\mathrm{GPIb}^{-/-}$mice are immunoresponsive to WT platelets and thus can be utilized in a model of FNIT, as we previously described in $\beta 3^{-/-}$mice (34).

Miscarriage occurred in most of the mice with anti-GPIba-mediated FNIT. To compare the pathogenesis of FNIT mediated by anti-GPIb $\alpha$ and anti- $\beta 3$ integrin (anti- $\beta 3$ ) antibodies in these two strains of syngeneic mice, we determined antibody titers in $\mathrm{GPIb}^{-/-}$and $\beta 3^{-/-}$females after 2 transfusions of $10^{8}$ WT platelets $(34,35)$. There was no significant difference (data not shown) in the mean titers of anti-GPIb $\alpha$ and anti- $\beta 3$ antibodies.

The immunized GPIb $\alpha^{-/-}$and $\beta 3^{-/-}$females and naive GPIb $\alpha^{-/-}$and $\beta 3^{-/-}$females (negative controls) were bred with WT males to mimic human FNIT $(34,35)$. We found, unexpectedly, that it was very difficult to obtain thrombocytopenic $\mathrm{GPIb}^{+/-}$pups, and miscarriage occurred in most of the mice with anti-GPIb $\alpha$-mediated FNIT ( 25 of $30,83.3 \%$ ), which was far more frequent than that mediated by anti- $\beta 3$ (10 of 26, 37\%; $P<0.0005$ ) (Figure 2A) and compared with naive

\section{Figure 2}

Miscarriage occurred in most mice of the anti-GPIb $\alpha$-mediated FNIT model. (A) GPIb $\alpha^{-/-}$and $\beta 3^{-/-}$mice were transfused twice with $10^{8}$ gel-filtered WT platelets. After breeding of immunized females with WT males, far higher rates of miscarriage occurred in the antiGPIb $\alpha$-mediated FNIT model compared with the anti- $\beta 3$ model (25 of $30,83.3 \%$ versus 10 of $27,37 \% ; P<0.0005$ ). (B) The immunized $\mathrm{GPIb \alpha}^{-/-}$mice at the time of miscarriage (around 16.5-18.5 d.p.c.) and naive $\mathrm{GPIb \alpha}^{-1-}$ mice at 17.5 d.p.c. were dissected. Much smaller conceptuses were found in the immunized $\mathrm{GPIb}^{-/-}$females undergoing miscarriage. Scale bars: $1 \mathrm{~cm}$. (C) The average number of pups per litter of females in the immunized $\mathrm{GPIb}^{-/}$group was smaller than that of the immunized $\beta 3^{--}$group $(P<0.0005)$.

controls ( 0 of $17,0 \% ; P<0.0001)$. Miscarriage was detected around day 16.5 to 18.5 of pregnancy. When the females were dissected after miscarriage, the conceptuses were much smaller than those of naive controls (Figure 2B), which was likely due to the resorption of conceptuses when miscarriage occurred. For the immunized females with a successful pregnancy, thrombocytopenia was observed in live $\mathrm{GPIb}^{+/-}$pups $\left(209.8 \pm 13.9 \times 10^{9} / 1\right.$ versus $286.7 \pm 12.4 \times 10^{9} / 1$ in naive control mice, $P<0.001)$ and $\beta 3^{+/-}$FNIT pups $\left(151.9 \pm 12 \times 10^{9} / 1\right.$ versus $\left.341.5 \pm 3.7 \times 10^{9} / 1, P<0.001\right)$. Furthermore, we observed that the average number of pups per litter in the immunized GPIb $\alpha^{-/-}$ group was lower than in the $\beta 3^{-/-}$group $(0.4 \pm 0.2$ pups versus $3.3 \pm 0.8$ pups, $P<0.0005)$; naive $\mathrm{GPIb}^{-/-}$and $\beta 3^{-/-}$mice generated $8.8 \pm 0.6$ and $8.2 \pm 1.3$ pups per litter, respectively (Figure $2 \mathrm{C}$ ). These data suggest that the maternal immune response against the GPIb $\alpha$ antigen caused frequent fetal mortality, which is significantly more severe than that in anti- $\beta 3$-mediated FNIT.

To exclude the potential effects of maternal GPIb $\alpha$ deficiency and maternal immune status on miscarriage incidence, we bred immunized $\mathrm{GPIb}^{-/-}$females with heterozygous $\left(\mathrm{GPIb}^{+/-}\right)$males. Assuming a Mendelian ratio, it was expected that half of the pups would be $\mathrm{GPIb}^{-/-}$and half would be GPIb $\alpha^{+/-}$. Surprisingly, we did not find any $\mathrm{GPIb}^{+/-}$pups, and all 11 pups delivered from these breeders were $\mathrm{GPIb}^{-/-}(P<0.005)$. This suggests that maternal GPIb $\alpha$ deficiency and maternal immune status did not significantly affect pregnancy outcome in the anti-GPIb $\alpha$-mediated FNIT model. Instead, it appears that the maternal immune response to fetal GPIb $\alpha$ caused severe pathology in the GPIb $\alpha$ antigen-positive fetuses (i.e., fetal death).

Excessive fibrin deposition and apoptosis/necrosis in the placenta of immunized GPIb $\alpha^{-1-}$ females. Pregnancy is associated with an acquired hypercoagulable state that can cause gestational vascular complications, especially in the presence of other prothrombotic risk factors (36). Recently, it has been demonstrated that thrombus formation in the placenta can lead to spontaneous fetal loss (37). To test whether microthrombus formation was enhanced in the placenta of immunized GPIb $\alpha^{-/-}$mice, we used anti-fibrin antibody to stain the 14.5 days post coitum (d.p.c.) placentas (i.e., before miscarriage occurred) from immunized $\mathrm{GPIb} \alpha^{-/-}$and $\beta 3^{-/-}$mice. Compared with the $\beta 3^{-/-}$group, immunized FNIT mothers with anti-GPIb $\alpha$ antibodies exhibited significantly more fibrin deposition in the placenta $(P<0.0005)$, suggesting that thrombus formation was enhanced in the placenta of $\mathrm{GPIb}^{-/-}$females carrying GPIb $\alpha^{+/-}$fetuses (Figure 3, A and B). TUNEL staining revealed that significantly more apoptosis/necrosis occurred in placentas from immunized pregnant $\mathrm{GPIb \alpha}^{-/-}$mice, compared with naive $\mathrm{GPIb}^{-/-}$mice or immunized $\beta 3^{-/-}$mice $(P<0.0001)$ (Figure 4, A and B). By introducing FITC-dextran into the blood circulation of 15.5-d.p.c. pregnant mice (38), we found that compared 

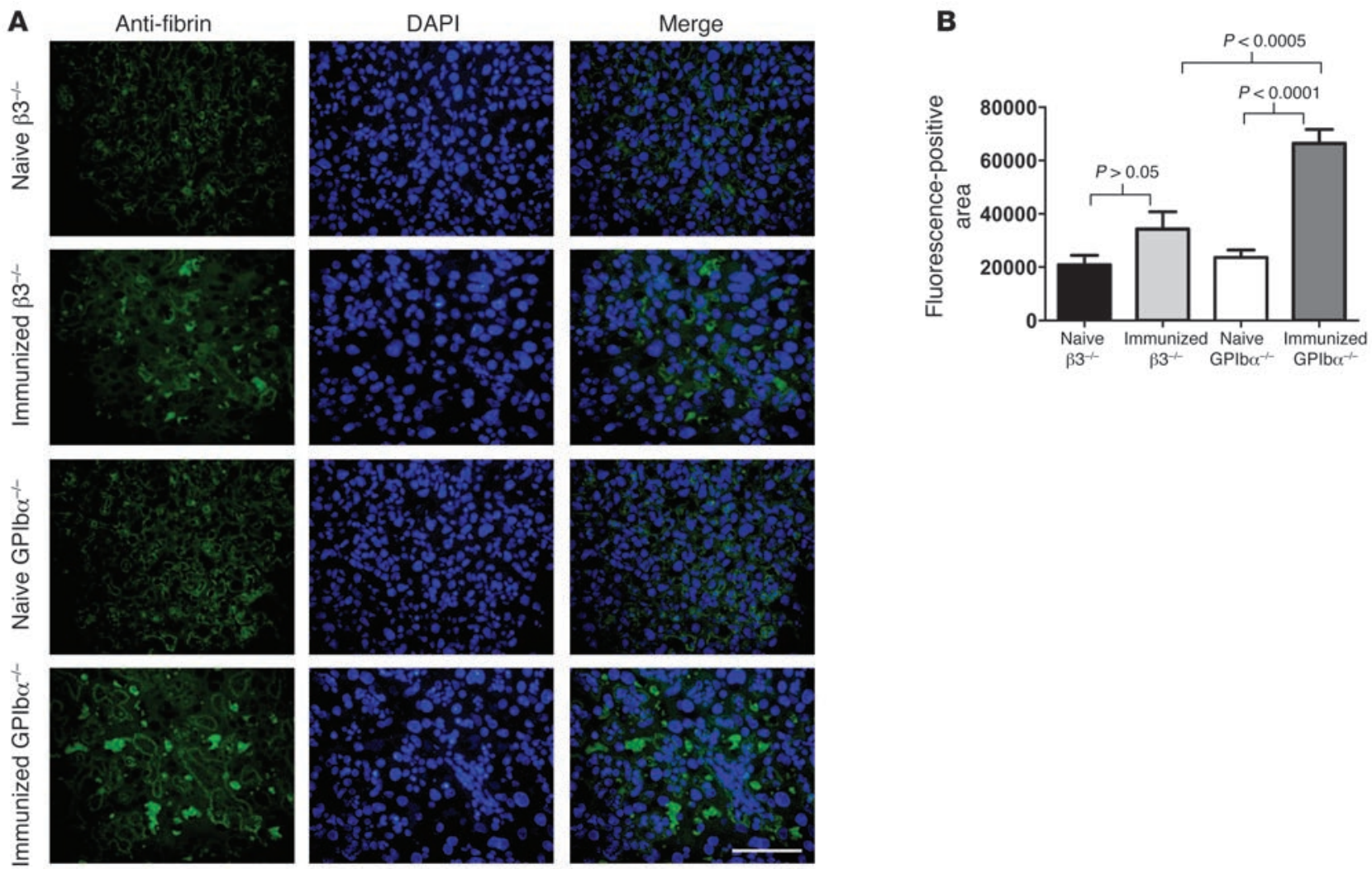

Figure 3

Significantly more fibrin deposition was observed in placentas from immunized GPIb $\alpha^{-1-}$ mice. (A) Representative pictures of 14.5-d.p.c. placenta from different pregnant females (as indicated), stained with anti-fibrin antibody. Scale bar: $100 \mu \mathrm{m}$. (B) Quantitative analysis detected significantly more fibrin deposition in placentas from immunized $\mathrm{GPIb}^{-/-}$mice, compared with immunized $\beta 3^{-/-}$mice $(n=6-10$ mice per group).

with naive pregnant $\mathrm{GPIb}^{-/-}$mice, the amount of FITC-dextran reaching the fetal placenta circulation was significantly reduced in immunized pregnant GPIb $\alpha^{-/-}$mice $(P<0.0001)$, suggesting that fetal blood supply was markedly impaired in affected placentas (Figure 5, A and B). As a control, FITC-dextran infusion into other organs, such as liver, kidney, and spleen, was found to be comparable in naive and immunized pregnant GPIb $\alpha^{-/-}$mice (Supplemental Figure 1, A and B; supplemental material available online with this article; doi:10.1172/JCI57850DS1). Interestingly, anti-thrombotic treatment of immunized pregnant GPIb $\alpha^{-/-}$mice with low-dose warfarin $(5 \mu \mathrm{g} / \mathrm{d})$ alleviated miscarriage in this FNIT model (8 of 15 , $53.3 \%$ versus 25 of $30,83.3 \%$; $P<0.05$ ). These data demonstrated, for the first time to our knowledge, that maternal antibodies to platelet GPIb $\alpha$ cause thrombus formation in the placenta and impair placental function, which likely accounts for the more frequent miscarriages observed in anti-GPIbo-mediated FNIT.
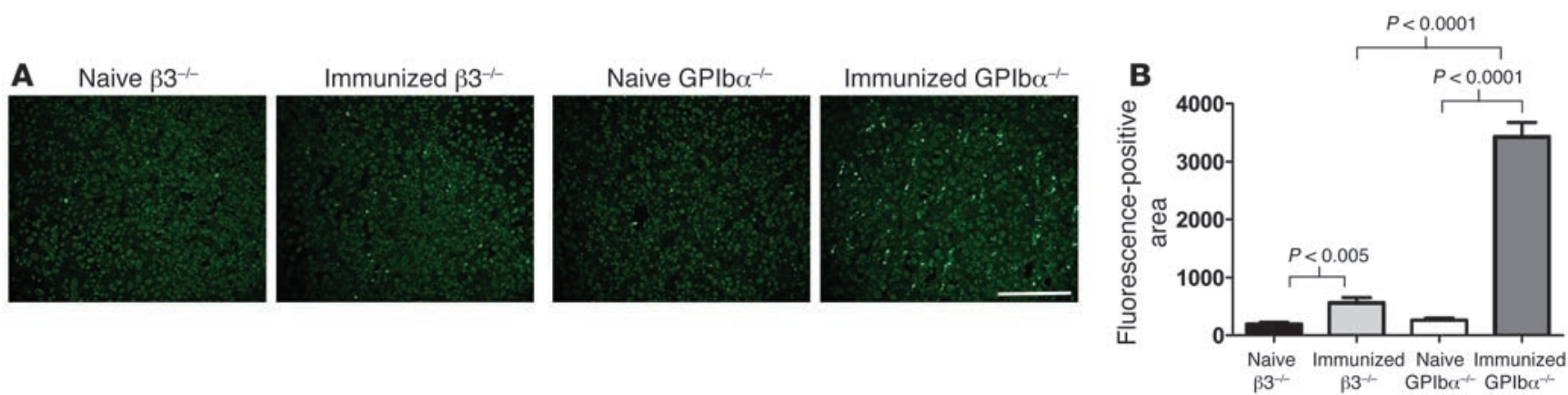

Figure 4

Significantly more apoptosis/necrosis was observed in placentas from immunized GPIb $\alpha^{-/-}$mice. (A) Representative pictures of the 14.5-d.p.c. placentas from different pregnant females with TUNEL staining. Scale bar: $200 \mu \mathrm{m}$. (B) Quantitative analysis revealed that significantly more apoptosis/necrosis occurred in placentas from immunized GPIb $\alpha^{-/-}$mice compared with naive GPIb $\alpha^{-/-}$mice or immunized $\beta 3^{-/-}$mice $(n=4-6$ mice per group). 
A

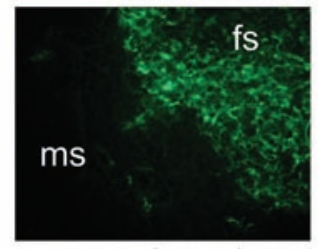

Naive GPIb $\alpha^{-1-}$

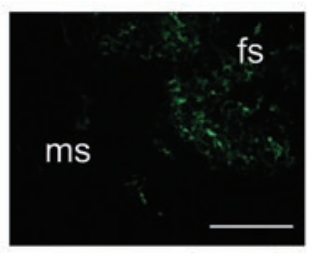

Immunized GPIb $\alpha^{-1-}$

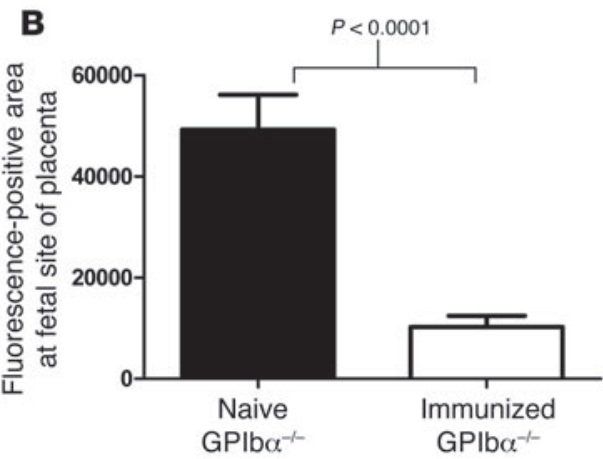

Anti-GPIb $\alpha$ antiserum activated antigen-positive platelets, enhanced fibrin formation in vitro, and accelerated thrombosis in vivo. Activated platelets can generate a procoagulant surface that promotes thrombin generation and fibrin formation (17-19). It has been reported that some anti-platelet autoantibodies in ITP patients stimulate platelets $(39,40)$, and anti-GPIb $\alpha$ antibodies may activate platelets under certain circumstances in a murine model (31). As described above, enhanced fibrin formation and apoptosis/ necrosis were found in the placentas of mothers with anti-GPIb $\alpha$ antibodies. We suspected that anti- $\beta 3$ and anti-GPIb $\alpha$ antibodies present in our murine model of FNIT might have differing effects

\section{Figure 5}

Significantly lower fetal blood supply was observed in placentas from immunized $\mathrm{GPIb \alpha}^{-1-}$ mice. (A) FITC-dextran was infused into 15.5-d.p.c. pregnant $\mathrm{GPIb}^{-1-}$ mice. Representative pictures of placentas are shown. ms, maternal side; fs, fetal side. Scale bar: $200 \mu \mathrm{m}$. (B) Quantitative analysis of the fluorescence-positive area at the fetal side of the placenta suggested that the fetal blood supply was severely impaired in immunized pregnant GPIb $\alpha^{-/-}$mice compared with naive $\mathrm{GPIb} \alpha^{-/-}$ mice $(P<0.0001, n=4-6$ mice per group).

on fetal platelet function, effecting the observed differences in fibrin formation and apoptosis/necrosis in the placenta.

Using aggregometry, we found that whereas anti- $\beta 3$ serum inhibited aggregation, anti-GPIb $\alpha$ antiserum enhanced ADP-induced WT platelet aggregation in platelet-rich plasma (PRP) (Figure 6A). Similar effects were observed for antiserum in PRP from GPIb $\alpha^{+/-}$mice, which more appropriately reflects the in vivo platelet phenotype in $\mathrm{GPIb}^{+/-}$fetuses from immunized pregnant $\mathrm{GPIb}^{-/-}$mice. In addition, anti-GPIb $\alpha$ antiserum, but not anti- $\beta 3$ serum, was able to induce mild platelet aggregation in WT PRP in the absence of agonist, and the platelet microaggregates were confirmed under light microscopy (Figure 6, B and C); this aggregation could be inhibited by RGD peptides (Supplemental Figure 2). We used WT platelets to specifically remove anti-GPIb $\alpha$ antibodies from antiserum and found that the preabsorbed anti-GPIb $\alpha$ serum failed to both enhance ADP-induced platelet aggregation and induce WT platelet aggregation in PRP (Supplemental Figure 3, A and B). Furthermore, the effects of murine anti-GPIb $\alpha$ antiserum on WT platelet aggregation (Figure 6, A and B) were not observed with $\mathrm{GPIb}^{-/-}$platelets (Supplemental Figure 3, C and D). We also found that anti-GPIb $\alpha$ polyclonal serum induced WT platelet $\mathrm{P}$-selectin expression and $\beta 3$ integrin activation, which facilitated JON/A and fibrinogen binding (Figure 7, A-C). These effects seem to have been independent
A

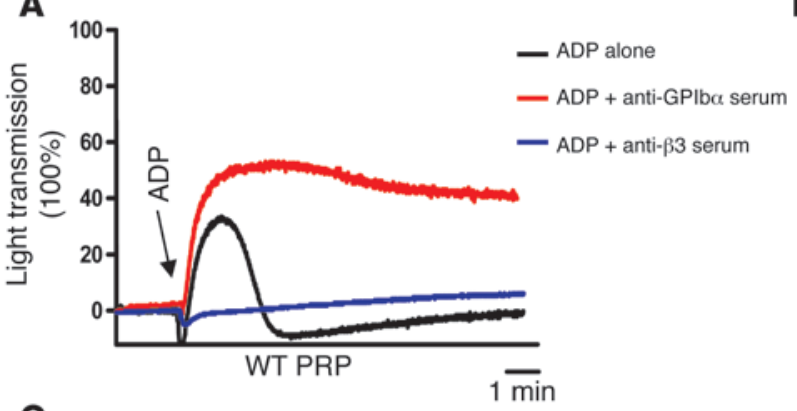

B

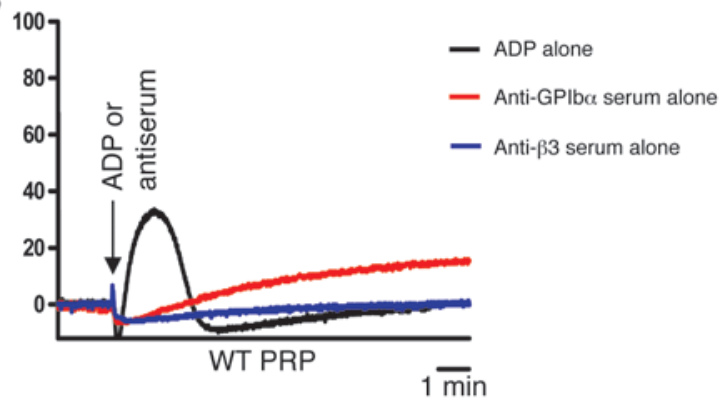

C

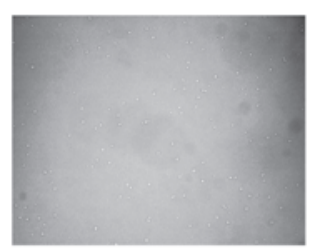

Preimmune serum

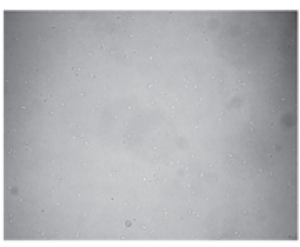

Anti- $\beta 3$ serum

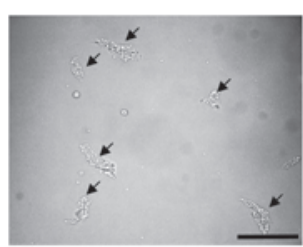

Anti-GPIb $\alpha$ serum

\section{Figure 6}

Anti-GPIb $\alpha$ antiserum cause antigen-positive platelet activation in vitro. (A) Polyclonal anti- $\beta 3$, anti-GPIb $\alpha$, or preimmune serum was incubated with WT PRP prior to induction of platelet aggregation with $2 \mu \mathrm{M}$ ADP. Anti-GPIb $\alpha$ serum enhanced ADP-induced WT platelet aggregation, while anti- $\beta 3$ serum inhibited aggregation. (B) Anti- $\beta 3$ serum alone (blue curve), anti-GPlb $\alpha$ serum alone (red), or ADP ( $2 \mu \mathrm{M}$; black) was added to WT PRP at 2 minutes of reaction (arrow). Anti-GPIb $\alpha$, but not anti- $\beta 3$, serum was able to induce mild platelet aggregation in WT PRP in the absence of soluble agonist. (C) The platelets represented in B were visualized under light microscopy. Arrows indicate platelet microaggregates. Scale bar: $50 \mu \mathrm{m}$. Results in $\mathbf{A}-\mathbf{C}$ are representative of 3 independent experiments. 

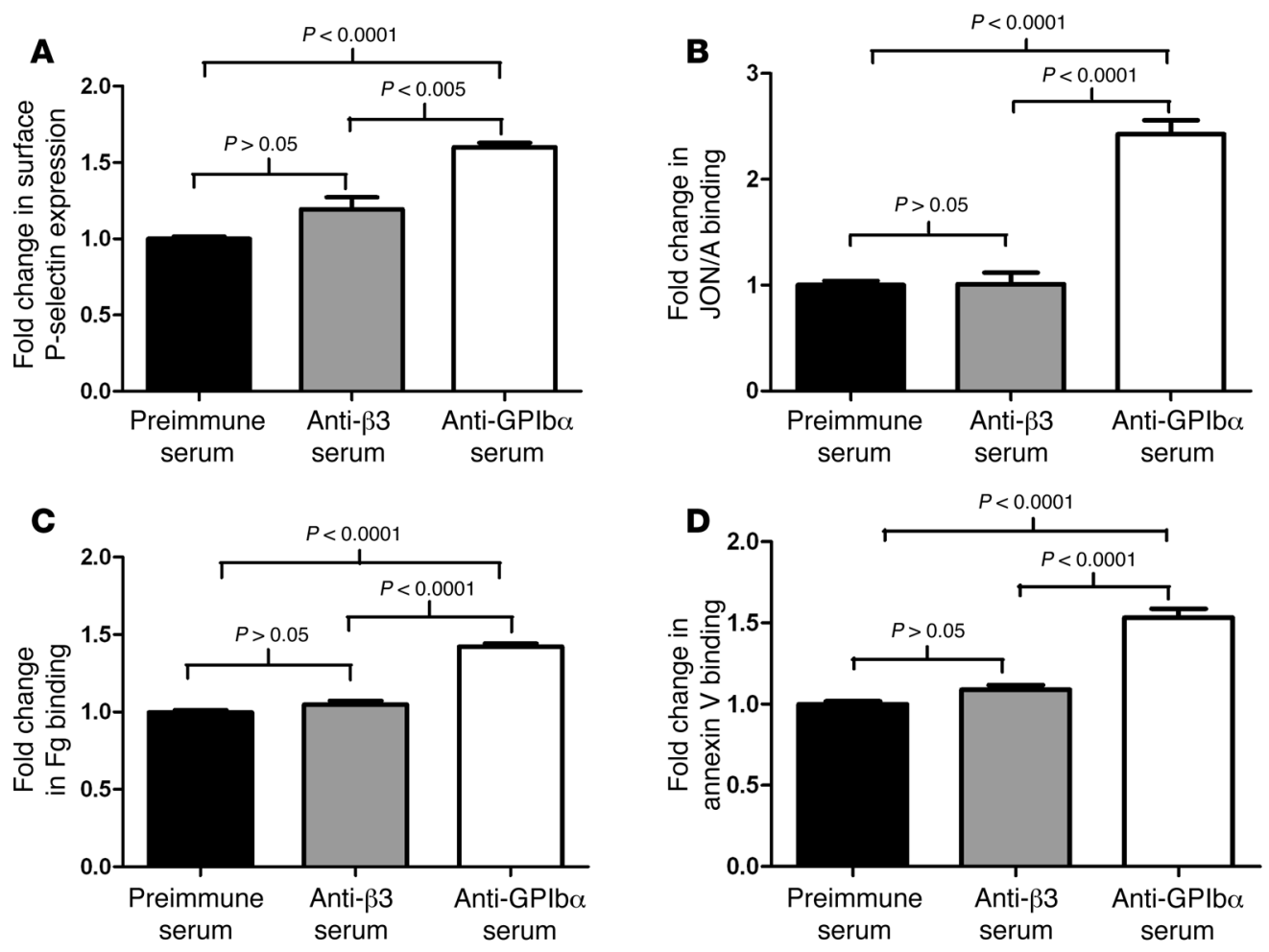

Figure 7

Anti-GPIb $\alpha$ polyclonal serum induces WT platelet P-selectin expression and enhance JON/A binding and fibrinogen binding. (A-C) Polyclonal anti- $\beta 3$, anti-GPIb $\alpha$, or preimmune serum was incubated with the gel-filtered WT platelets and then stained by FITC-labeled anti-P-selectin antibody, PE-labeled JON/A antibody (specifically recognizing the active form of $\beta 3$ integrin), or Alexa Fluor 488-labeled fibrinogen (Fg). Compared with anti- $\beta 3$ serum or preimmune serum, anti-GPIb $\alpha$ polyclonal serum-treated WT platelets exhibited significantly more P-selectin expression, JON/A binding, and Fg binding $(P<0.0001)(n=3-4$ mice per group). (D) Anti-GPIb $\alpha$ polyclonal serum caused significantly more PS exposure than anti- $\beta 3$ serum or preimmune serum $(P<0.0001)(n=3-4$ mice per group).

of genetic background, since similar results were also observed in C57BL/6J mice (Supplemental Figure 4). The antiserum also induced PS surface exposure, a marker of early platelet activation (41), on WT platelets (Figure 7D). These data demonstrate that antiGPIb $\alpha$ polyclonal antibodies are able to specifically induce GPIb $\alpha$ positive platelet activation and aggregation.

PS exposure on the platelet surface promotes the conversion of prothrombin into thrombin that mediates fibrin formation (17-19). In addition, the anti-GPIb $\alpha$ polyclonal antibodies generated in our antiGPIb $\alpha$ FNIT model may block thrombin binding to platelet GPIb $\alpha$ $(42,43)$, which may increase free thrombin, further enhancing the conversion of fibrinogen to fibrin. To test this, we purified IgG from anti-GPIb $\alpha$ serum and preimmune GPIb $\alpha$ serum. We found that anti-GPIb $\alpha$ IgG significantly inhibited the binding of $\alpha$-thrombin to murine WT platelets (Figure 8A). Thus, enhancement of PS exposure and thrombin generation as well as releasing thrombin from GPIb $\alpha$ may synergistically contribute to fibrin formation.

Using a perfusion chamber to investigate fibrin formation in vitro, we found that anti-GPIb $\alpha$ antiserum significantly accelerated fibrin network formation on platelets, compared with preimmune serum (Figure 8, B and C). In contrast, anti- $\beta 3$ antiserum showed the trend of delaying fibrin formation (data not shown). In an intravital microscopy thrombosis model $(44,45)$, anti-GPIb $\alpha$ antiserum significantly accelerated thrombus formation (Figure 9, A and B), although anti-GPIb $\alpha$ antibodies inhibited the early stage of platelet-vessel wall interaction, which is mainly mediated by the engagement of GPIb $\alpha$ and von Willebrand factor (46); half of the $\mathrm{BALB} / \mathrm{c}$ mice treated with anti-GPIb $\alpha$ serum, but none of those treated with preimmune serum, developed occlusive thrombi (5 of 10 versus 0 of $10, P<0.01$ ), despite thrombocytopenia in the antiGPIb $\alpha$ antiserum-injected mice.

IVIG and anti-FcRn prevented miscarriage in anti-GPIba-mediated FNIT. Miscarriage is a devastating consequence, and thus, antenatal management is required. In previous work with the $33^{-/-}$model of FNIT, we found that maternal administration of IVIG ameliorated FNIT $(34,35)$, consistent with reported clinical data $(1,8)$, although the clinical data from different groups vary $(1,8,47)$. Here, we investigated whether mice with anti-GPIb $\alpha$-mediated FNIT similarly responded to IVIG treatment. This is intriguing, since we previously reported that in a murine model, IVIG did not effectively ameliorate anti-GPIb $\alpha$-mediated ITP (48), which seems to be true in human ITP patients (49). Interestingly, we found that maternal administration of IVIG during pregnancy completely prevented miscarriage (0 of 5 versus 25 of $30, P<0.0005)$ (Figure 10A), increased neonatal platelet count $\left(265.3 \pm 12.1 \times 10^{9} / 1\right.$ versus $\left.209.8 \pm 13.9 \times 10^{9} / 1, P<0.05\right)$, and increased the number of pups per litter $(6.4 \pm 1.2$ versus $0.4 \pm 0.2$, $P<0.0001$ ) in the anti-GPIb $\alpha$-mediated FNIT (Figure 10, B and C).

FcRn plays an important role in extending IgG half-life in the circulation and mediating the transplacental transport of IgG from the mother to the fetus (50-52). We recently demonstrated that blockade of FcRn is an important mechanism of IVIG action and that anti-FcRn may be a potential new therapy for FNIT (35). However, 

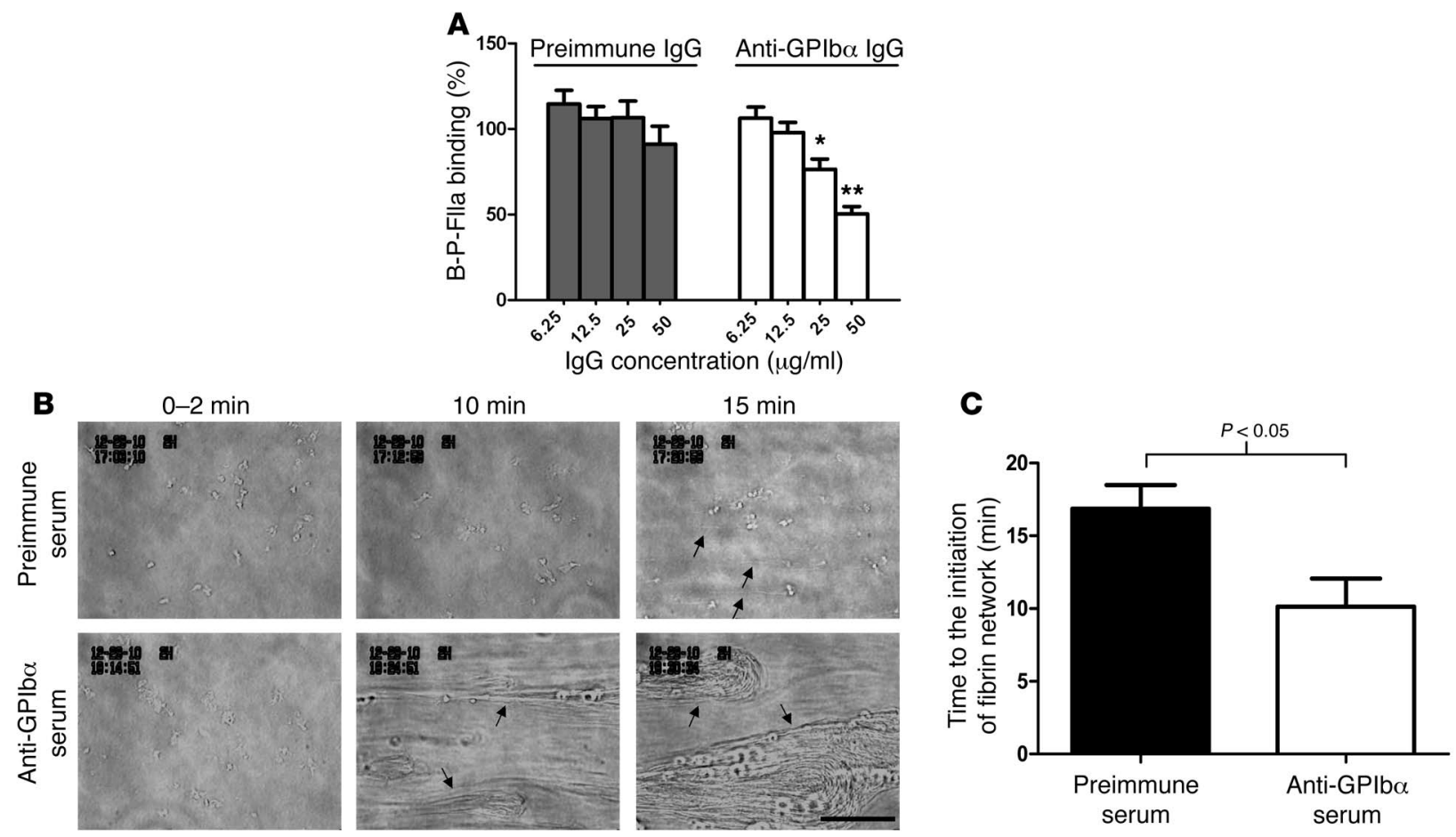

\section{Figure 8}

Anti-GPIb $\alpha$ antibodies inhibit $\alpha$-thrombin binding to WT platelets, and anti-GPIb $\alpha$ antiserum enhances fibrin formation in vitro. (A) The purified anti-GPIb $\alpha$ polyclonal antibodies significantly inhibited the binding of $\alpha$-thrombin tagged with biotin/PPACK (B-P-FIla) to murine WT platelets $\left({ }^{\star} P<0.05 ;{ }^{* *} P<0.005 ; P\right.$ values represent comparisons between IgG and anti-Gplba IgG groups at the same IgG concentrations, respectively). (B) Representative pictures of in vitro fibrin formation. Arrows indicate fibrin fiber formation on platelets. Scale bar: $50 \mu \mathrm{m}$. (C) Quantitative analysis of fibrin formation showed that anti-GPIb $\alpha$ polyclonal serum significantly shortened the time to form a fibrin network, compared with preimmune serum ( $n=8-10$ per group).

whether anti-FcRn treatment is able to prevent miscarriage has not been studied. This is particularly important, since it is completely unknown whether anti-FcRn will increase the local inflammatory response after it targets trophoblasts or endothelial cells in the placenta, which may enhance blood coagulation and exacerbate fibrin deposition. To test this, we used an anti-FcRn mAb to treat the immunized GPIb $\alpha^{-/-}$mice during pregnancy. Miscarriage was prevented ( 0 of 4 versus 25 of 30, $P<0.0005$ ) (Figure 10A), and both neonatal platelet count $\left(261.2 \pm 18.4 \times 10^{9} / 1\right.$ versus $209.8 \pm 13.9 \times 10^{9} / 1$, $P<0.05)$ and the number of pups per litter $(4.5 \pm 0.3$ versus $0.4 \pm 0.2$, $P<0.0001)$ increased (Figure 10, B and C). Thus, in these animal models, we demonstrated that IVIG and anti-FcRn are both effective therapies for treating anti-GPIb $\alpha$-mediated FNIT and preventing the prevalent fetal mortality observed in this devastating disease.

\section{Discussion}

The severity and prevalence of anti-GPIb $\alpha$-mediated FNIT have not been adequately studied. In the current study, we established two new murine models of FNIT using syngeneic GPIb $\alpha^{-/-}$and $\beta 3^{-/-}$mice. Surprisingly, we found that with anti-GPIb $\alpha$-mediated FNIT, most fetuses died and more than $83 \%$ of pregnant GPIb $\alpha^{-/-}$ mothers did not deliver any pups. This miscarriage rate was far more severe than with anti- $\beta 3$-mediated FNIT and revealed nonclassical FNIT (i.e., no bleeding manifestations). Anti-fibrin and TUNEL staining demonstrated that fibrin deposition and apoptosis/necrosis were markedly enhanced in the placenta from immunized GPIb $\alpha^{-/-}$FNIT mice, compared with immunized $\beta 3^{-/-}$FNIT mice. We also observed that anti-GPIb $\alpha$ antibodies induced antigen-positive platelet activation, enhanced fibrin formation in vitro, and accelerated thrombus formation in vivo. Our data suggest that frequent miscarriage caused by anti-GPIb $\alpha$ antibodies may mask the severity and the reported incidence of this life-threatening disease. Importantly, we demonstrated that the devastating fetal loss can be efficiently prevented by IVIG and anti-FcRn therapies.

Anti-GPIba-mediated FNIT has not been the subject of intensive study, since the reported incidence is rare. There is no report that the maternal immune response to fetal GPIb $\alpha$ may cause miscarriage in FNIT, although a genetic study suggested that the HPA-2 polymorphism (on GPIb $\alpha$ ), but not the HPA-1 polymorphism (on $\beta 3$ integrin), is associated with patients with recurrent spontaneous abortion (53). There are also case reports suggesting that anti-GPIb $\alpha$ complex antibodies were present in patients with habitual abortion (54). Anti-GPIb $\alpha$ antibodies in pregnant women with GPIb-IX deficiency are also associated with a few cases of intrauterine death (55-57). These observations in humans are consistent with our findings in the murine FNIT models in that miscarriages may occur in patients, accounting for the paucity of reported cases of anti-GPIb $\alpha$-mediated FNIT.

Other clinical indices and symptoms of human FNIT are also well reproduced in our murine models $(34,35)$. The GPIb $\alpha^{-/-}$female mice immunized with WT platelets in this model may mimic the human mothers who have had previous pregnancies in which the maternal immune system is exposed to fetal/neonatal antigenpositive platelets due to uterine injury during delivery $(58,59)$ and 
A
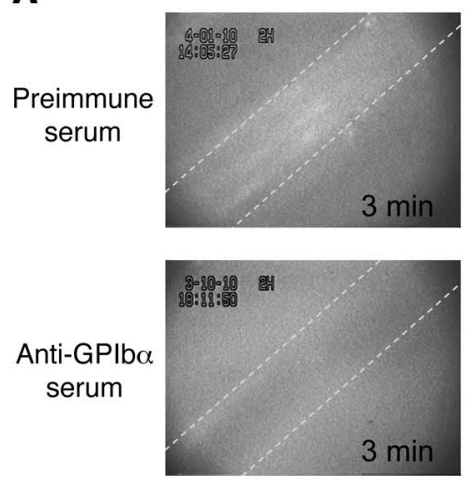
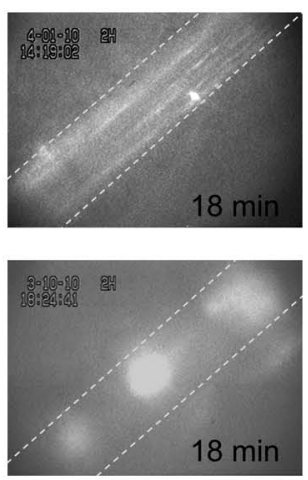
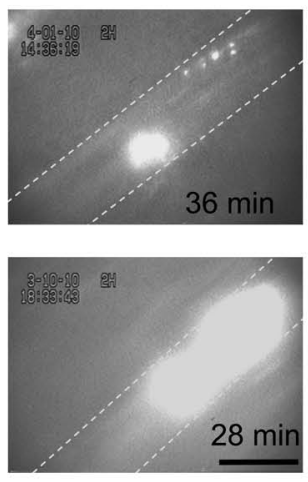

B

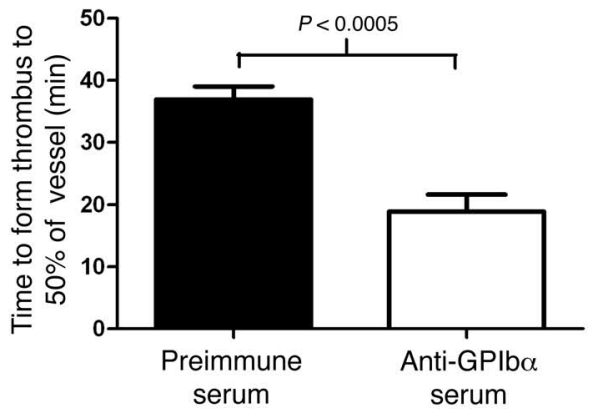

Figure 9

Anti-GPIb $\alpha$ antiserum accelerates thrombosis in vivo. (A) Representative pictures of thrombus formation in the mesenteric artery. Images of thrombus formation were recorded for 40 minutes using a video cassette recorder. Dashed lines denote the vessel wall. Scale bar: $100 \mu \mathrm{m}$. (B) Quantitative analysis of thrombus formation showed that anti-GPIb $\alpha$ polyclonal serum significantly accelerated thrombus formation in the WT $\mathrm{BALB} / \mathrm{c}$ mice compared with preimmune serum ( $n=6-8$ mice per group).

thus may generate anti-GPIb $\alpha$ antibodies. Maternal immunization against fetal platelet GPIb $\alpha$ may also occur during human pregnancy when fetal GPIb $\alpha$ antigen-positive platelets leak into the maternal circulation via fetomaternal hemorrhage $(58,59)$. Since (a) $\beta 3$ integrin (GPIIIa) is expressed on human placental syncytiotrophoblast microvilli that are in direct contact with maternal blood and may induce the immune response against HPA-1a on $\beta 3$ integrin in primiparous mothers $(60,61)$ and (b) GPIb $\alpha$ has been reported to be expressed on human endothelial cells under certain conditions (62-64), we cannot exclude the possibility that GPIb $\alpha$, like $\beta 3$ integrin, may also be expressed on placental syncytiotrophoblasts and endothelial cells, thus contributing to maternal anti-GPIb $\alpha$ antibody generation during pregnancy.

Miscarriage or pregnancy loss affects approximately $10 \%-30 \%$ of human pregnancies $(65,66)$. In the current study, we observed enhanced placental fibrin deposition in immunized $\mathrm{GPIb}^{-/-}$mice, compared with immunized $\beta 3^{-/-}$mice. Our in vitro data demonstrated that anti-GPIb $\alpha$, but not anti- $\beta 3$, antiserum specifically induced the activation and aggregation of antigen-positive platelets (Figure 6 and Figure 7, A-C). We also observed that some anti-GPIb $\alpha$ serum, but not anti- $\beta 3$ serum, from ITP patients induced platelet calcium mobilization, another indicator of platelet activation (C.M. Spring, G. Zhu, and H. Ni, unpublished observations). Furthermore, we demonstrated that anti-GPIb $\alpha$ antiserum enhanced PS expression (Figure 7D) and fibrin formation on platelets in vitro (Figure 8, B and $C$ ) and facilitated thrombus formation in vivo (Figure 9, A and B). The association between anti-GPIb $\alpha$ antibodies and enhanced thrombosis is in accordance with a human study in which antiGPIb $\alpha$ antibodies were detected in approximately $18 \%$ of lupus anticoagulant patients and the majority developed thromboembolic events, such as abortion and arterial and venous thrombosis (67). The possibility that thrombus formation in the placenta likely accounts for miscarriage is further supported by our findings that anti-thrombotic treatment of immunized pregnant GPIb $\alpha^{-/}$mice with low-dose warfarin $(5 \mu \mathrm{g} / \mathrm{d})$, which is able to traverse the placenta, alleviated miscarriage in this FNIT model.

In addition to platelet activation and PS expression induced by the anti-GPIb $\alpha$ antibodies, the interaction between $\alpha$-thrombin and platelet GPIb $\alpha(42,43)$ was also inhibited by these antibodies (Figure 8A).
A similar effect may also occur in human FNIT patients with antiGPIb $\alpha$ antibodies. Blocking thrombin binding to GPIb $\alpha$ would lead to increased free circulating thrombin, allow for increased cleavage of fibrinogen into fibrin, and activate platelets via proteaseactivated receptors 1 and 4 (PAR-1 and PAR-4), which may further enhance thrombosis. We indeed observed that platelets from these anti-GPIb $\alpha$-injected mice exhibited significantly higher P-selectin expression and JON/A binding and tended to form microaggregates (Supplemental Figure 5, A-C). Thus, anti-GPIb $\alpha$ antibodies may activate platelets and enhance platelet aggregation, as well as generating procoagulant surfaces or more circulating thrombin, which would enhance thrombus formation in affected placentas. The observed extensive thrombi and fibrin deposition in the placenta may not only block fetal blood supply, as indicated by FITC-dextran placental perfusion (Figure 5), but also directly cause the death of trophoblast cells (68), thus synergistically contributing to the higher miscarriage rate in anti-GPIb $\alpha$-mediated FNIT.

It is notable that our observations that anti-GPIb $\alpha$ antibodies activate platelets, enhance platelet aggregation, and generate a procoagulant status may be important in designing anti-thrombotic therapy. Anti-GPIba-based therapies are presently under preclinical investigations (ref. 69 and G. Zhu and H. Ni, unpublished observations). Since our findings suggest that intact anti-GPIb $\alpha$ antibodies might aggravate the severity of thrombosis, manufacturers of this potential therapy may need to take this into consideration and avoid this adverse effect by using monovalent Fab or Fv antibody fragments. In addition, since thromboembolic events occur in approximately $5 \%$ of ITP patients (70-72), it may be worthwhile to address whether these patients have anti-GPIb $\alpha$ antibodies.

FNIT is a devastating disease, and effective therapeutic intervention is currently limited and unstandardized (73). We previously demonstrated that maternal IVIG infusion ameliorated neonatal thrombocytopenia in the anti- $\beta 3$ FNIT model (34). However, we also reported that IVIG was not as effective in ameliorating thrombocytopenia caused by anti-GPIb $\alpha$ antibodies as compared with anti- $\beta 3$ antibodies in a murine ITP model (48), which was supported by subsequent studies in human ITP patients (49). It was therefore of interest to determine whether IVIG was efficacious in ameliorating thrombocytopenia in the anti-GPIb $\alpha$-mediated 
A

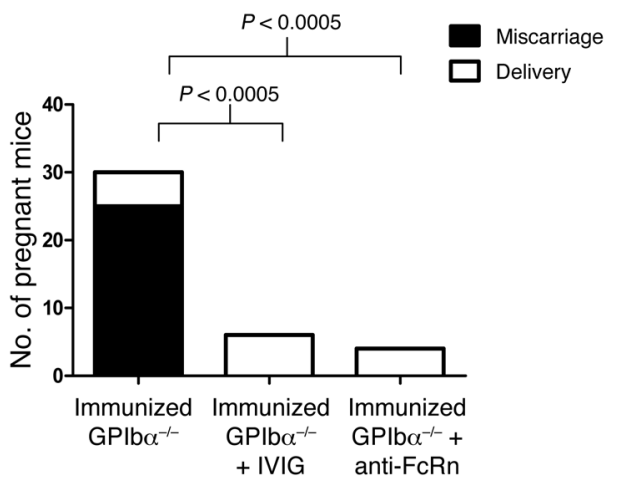

B

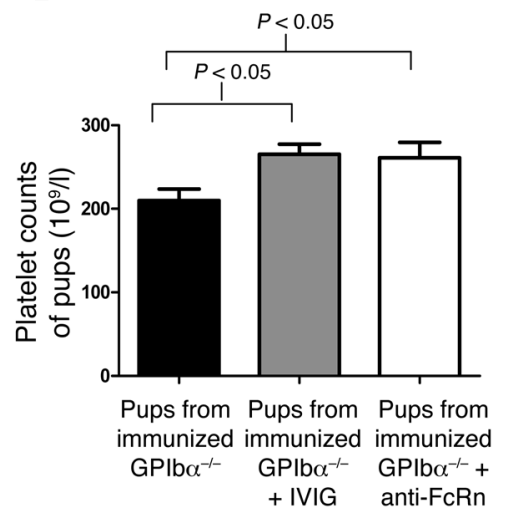

C

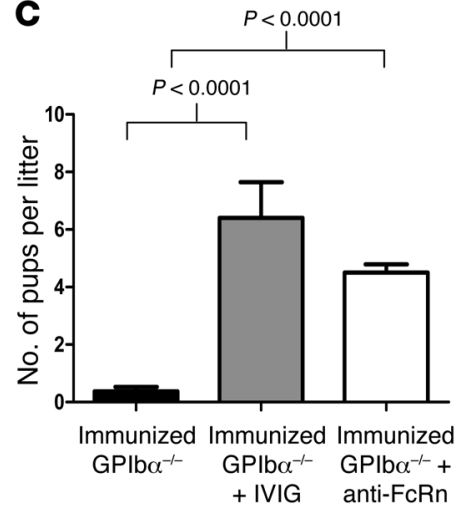

Figure 10

IVIG and anti-FcRn markedly prevented anti-GPIb $\alpha$-mediated FNIT. (A) Miscarriage in anti-GPIb $\alpha$-mediated FNIT was prevented by either IVIG ( 0 of $5,0 \%$ versus 25 of $30,83.3 \% ; P<0.0005)$ or anti-FcRn treatment $(0$ of $4,0 \%$ versus 25 of $30,83.3 \%$; $P<0.0005)$ when compared with untreated immunized mice. (B and C) Treatment of immunized pregnant GPIb $\alpha^{-/-}$mice with either IVIG or anti-FcRn significantly ameliorated neonatal thrombocytopenia and increased the average number of pups per litter, compared with nontreated groups.

FNIT model. Here, we observed that maternal IVIG treatment significantly prevented miscarriage and ameliorated neonatal thrombocytopenia; anti-FcRn treatment was similarly effective, but the effective dose of anti-FcRn was at least 100-fold lower. The mechanisms of IVIG and anti-FcRn therapy are still not fully understood, but blocking transplacental transport of anti-GPIb $\alpha$ antibodies may play an important role in the amelioration of FNIT.

It is currently unknown whether the maternal immune response against fetal GPIb $\alpha$ is indeed a significant cause of miscarriage in humans. Screening the polymorphisms of GPIba (e.g., HPA-2) in women experiencing miscarriage and habitual abortion and detecting anti-GPIb $\alpha$ antibodies during their pregnancies may provide important information to address this critical question. If antiGPIb $\alpha$ antibodies are indeed a risk factor for miscarriage in humans, identifying these women and treating them during early pregnancy with IVIG or anti-FcRn therapies may lead to the prevention of this nonclassical but devastating FNIT.

In summary, we found that the maternal immune response to fetal GPIb $\alpha$ caused an extremely high rate of miscarriage, which is different from the current definition of FNIT: a disease that is primarily characterized by bleeding symptoms in neonates. We further demonstrated, for the first time to our knowledge, that anti-GPIb $\alpha$ antibodies caused platelet activation and generated a procoagulant status, which led to prominent placental fibrin deposition and impaired placental function. The frequent miscarriage in the anti-GPIb $\alpha$ FNIT model may potentially explain why there are so few reported FNIT cases mediated by anti-GPIb $\alpha$ antibodies. Finally, we demonstrated that the devastating fetal loss can be efficiently prevented by maternal treatment with IVIG and anti-FcRn therapy.

\section{Methods}

Mice. GPIb $\alpha^{-/-}$mice were described previously $(74) . \beta 3^{-/-}$mice $(34,75)$ were provided by Richard $\mathrm{O}$. Hynes (Massachusetts Institute of Technology, Boston, Massachusetts, USA). Both GPIb $\alpha^{-/-}$and $\beta 3^{-/-}$mice were backcrossed to a $\mathrm{BALB} / \mathrm{c}$ background 10 times and bred to generate syngeneic genedeficient mice. Experiments were performed when mice were 6-10 weeks of age. BALB/c WT mice were purchased from Charles River. All mice were housed in the St. Michael's Hospital Research Vivarium.
Reagents. FITC-conjugated goat anti-mouse IgG was purchased from Sigma-Aldrich. IVIG (Gamunex) was obtained from Bayer Inc./Canadian Blood Services. The $1 \mathrm{G} 3$ hybridoma cell line producing anti-FcRn mAb $\left(\mathrm{IgG}_{1}\right)$ was purchased from ATCC.

Genotyping. We designed the primers for GPIb $\alpha$ genotyping: (a) forward primer (5'-AGTCTGGGAGGTGTGGAAGC-3') binds 5' of the pgk-neo cassette; (b) reverse primer 1 (5'-CACGAGACTAGTGAGACGTG-3') was neo (mutant) specific; (c) reverse primer 2 (GGTATCAAGATCCTC CAGCC) was WT specific. PCR products were $288 \mathrm{bp}$ (mutant) and $680 \mathrm{bp}$ (WT). The primers and methods for $\beta 3$ integrin genotyping were described previously (75).

Induction and treatment of fetal and neonatal immune thrombocytopenia. Gel-filtered WT platelets were prepared as previously described (45). GPIb $\alpha^{-/-}$and $\beta 3^{-/-}$females were immunized twice with $10^{8}$ gel-filtered WT platelets (containing GPIb $\alpha$ and $\beta 3$ integrin antigens) at weekly intervals $(34,35)$ and then bred with WT males. Naive GPIb $\alpha^{-/-}$and $\beta 3^{-/-}$females bred with WT males were used as controls. The antibody titration of the antiserum by flow cytometry was performed as we previously described (34). Body weight of females was monitored during pregnancy; a decrease in body weight (i.e., $\geq 1 \mathrm{~g}$ ) was indicative of miscarriage. For IVIG or anti-FcRn mAb treatment, IVIG $(1 \mathrm{~g} / \mathrm{kg})$ or anti-FcRn $(10 \mathrm{mg} / \mathrm{kg})$ was intraperitoneally injected into the immunized knockout females every 5 days, from 1.5 d.p.c. to delivery.

Platelet P-selectin expression, JON/A, and fibrinogen binding. Gel-filtered WT platelets $\left(2 \times 10^{7} / \mathrm{ml}\right)$ were incubated with polyclonal anti- $\beta 3$, anti-GPIb $\alpha$, or preimmune serum (1:10 serum dilution for P-selectin expression and fibrinogen binding; 1:50 dilution for JON/A binding). After 1 hour incubation, the samples were washed with PBS by centrifugation at $600 \mathrm{~g}$ for 10 minutes. FITC-labeled anti-P-selectin antibody (BD Biosciences), PE-conjugated JON/A antibody (Emfret Analytics), or Alexa Fluor 488-conjugated fibrinogen (Invitrogen) was then added to the platelets and incubated for 1 hour, followed by detection on a FACSCalibur II flow cytometer (BD Biosciences).

Anti-fibrin and TUNEL staining. The placenta samples were collected from 14.5-d.p.c. knockout females and fixed in formalin. The 4- $\mu \mathrm{m}$ tissue slides were deparaffinized and then dehydrated. After antigen unmasking, the slides were blocked with normal goat serum. Fibrin was stained with a mouse anti-human fibrin antibody (T2G1, Accurate Biochemicals), which cross-reacts with mouse fibrin, but not fibrinogen, coupled to Alexa Fluor 488 as per the manufacturer's protocol (Invitrogen). The nuclei were counterstained with DAPI (Sigma-Aldrich). TUNEL staining of the placenta was 
performed according to the manufacturer's instructions (Roche Applied Sciences). The fluorescence pictures were randomly taken under a Nikon E800 microscope. The fluorescence-positive areas were analyzed by Image J software (http://rsbweb.nih.gov/ij/).

Placental perfusion studies. FITC-dextran (MW 2,000,000; Sigma-Aldrich) was dissolved in distilled water and infused into 15.5-d.p.c. naive or immunized GPIb $\alpha^{-/-}$mice $(80 \mathrm{mg} / \mathrm{kg}$ mice $)$ via the tail vein, and 15 minutes later, the placentas and control organs (i.e., liver, kidney, and spleen) were isolated and snap-frozen (38). Serial frozen sections were assayed and photographed under a Nikon E800 microscope. The fluorescence-positive area at the fetal side of the placenta was analyzed using ImageJ software.

Platelet aggregation assays. Platelet aggregation was performed as we previously described (45). $25 \mu \mathrm{l}$ anti- $\beta 3$, anti-GPIb $\alpha$, or pre-immune serum was incubated with $250 \mu \mathrm{lWT}$ or $\mathrm{GPIb}^{-/-} \mathrm{PRP}\left(3 \times 10^{8}\right.$ platelets $\left./ \mathrm{ml}\right)$ for 10 minutes prior to induction of aggregation with ADP. To test the ability of the antiserum to induce platelet aggregation, serum alone was added to PRP after 2 minutes of reaction. These platelets were then taken from the aggregometer and stained with FITC-labeled Annexin V (BD Biosciences), which binds phosphatidylserine on platelets (41). For anti-GPIb $\alpha$ absorption by WT platelets (76), $500 \mu \mathrm{l}$ anti-GPIb $\alpha$ serum was incubated with $6 \times 10^{8} \mathrm{WT}$ platelets for 2 hours and then centrifuged at $3000 \mathrm{~g}$ for 5 minutes, and the process was repeated 3-4 times. The absorption efficiency was tested by using a flow cytometer (BD Biosciences).

IgG purification and $\alpha$-thrombin binding to platelets. Using protein G-conjugated beads (GE Healthcare), we purified IgG from preimmune GPIb $\alpha$ serum and anti-GPIb $\alpha$ antiserum based on the manufacturer's instructions. After being dialyzed in PBS at $4^{\circ} \mathrm{C}$ overnight, the purified IgG was concentrated using polyethylene glycol (PEG, MW 10,000; SigmaAldrich). The purified C57BL/6J platelets $\left(2 \times 10^{7} / \mathrm{ml}\right)$ were incubated with $25 \mathrm{nM} \alpha$-thrombin (approximately the $K_{D}$ of binding to platelet GPIb $\alpha$ ) blocked in the active site with biotin-conjugated D-phenylalanylL-prolyl-L-arginine chloromethyl ketone (PPACK; Haematologic Technologies), with or without the addition of anti-GPIb $\alpha$ or preimmune IgG. The bound biotin-PPACK-thrombin was revealed by addition of Alexa Fluor 488-conjugated streptavidin, followed by measurement on a FACSCalibur II flow cytometer (42).

In vitro fibrin formation in perfusion chambers. The in vitro fibrin formation assays were performed using methods slightly modified from those previously reported (77). In brief, WT platelets were coated to the chamber under stasis for 10-20 minutes, followed by 5 minutes perfusion of $1 \%$ BSA blocking buffer at a shear rate of 250/s. Either anti-GPIb $\alpha$ or preimmune serum (1:6 dilution in HEPES buffer, $120 \mu \mathrm{l}$ ) was perfused into the platelet-coated chamber at $250 / \mathrm{s}$. Subsequently, chambers were perfused with citrate-anticoagulated WT platelet-poor plasma and $\mathrm{CaCl}_{2}$-containing medium at 250/s. During the 25-minute perfusion, fibrin formation was monitored and recorded under a Zeiss Axiovert 135 inverted microscope ( $\times 20$ objective). The time to initiation of the fibrin network was determined under microscopy as previously described (77). Anti-fibrin staining was performed to confirm the fibrin formation.

Intravital microscopy thrombosis model. Intravital microscopy was performed as we previously described (44-46). Anti-GPIb $\alpha$ or preimmune serum (10 $\mu \mathrm{l} / \mathrm{g}$ body weight) was injected into 3- to 4-week-old WT BALB/c mice, and then the injury of mesenteric arteriole was induced by ferric chloride. Thrombus formation was monitored for 40 minutes under a Zeiss microscope. For quantitative analysis, we regarded the time as 40 minutes if the thrombus failed to reach $50 \%$ of arteriolar calibre.

Statistics. Data in all figures with error bars are presented as mean \pm SEM. Data were analyzed using Student's unpaired $t$ test ( 2 tailed) or $\chi^{2}$ test as indicated. A $P$ value less than 0.05 was considered significant.

Study approval. The experimental procedures on mice were approved by the Animal Care Committee of St. Michael's Hospital, Toronto, Ontario, Canada.

\section{Acknowledgments}

This work was supported by Canadian Institutes of Health Research, Equipment Funds from St. Michael's Hospital, Canadian Blood Services, Canada Foundation for Innovation, and by NIH grant HL-42846. C. Li is a recipient of the Connaught Scholarship and Laboratory Medicine and Pathobiology Departmental Fellowships, University of Toronto; S. Piran is a recipient of the Ontario Graduate Scholarship; S. Lang is a recipient of the Heart and Stroke Foundation of Canada (Ontario) Master's Studentship Award and Ph.D. Graduate Fellowship from Canadian Blood Services; E.K. Simpson is a recipient of the Heart and Stroke Foundation of Canada/Ontario Graduate Scholarship in Science and Technology. We thank John W. Semple and Gerald Prud'homme for their advice and discussion during this study and Christopher M. Spring and Xun Fu for their help in editing the manuscript.

Received for publication March 9, 2011, and accepted in revised form August 26, 2011.

Address correspondence to: Heyu Ni, Canadian Blood Services and Department of Laboratory Medicine and Pathobiology, St. Michael's Hospital, University of Toronto, Room 420, LKSKI Keenan Research Center, 209 Victoria Street, Toronto, Ontario, Canada M5B 1W8. Phone: 416.847.1738; Fax: 416.864.5826; E-mail: nih@smh.ca.
1. Bussel JB, Primiani A. Fetal and neonatal alloimmune thrombocytopenia: progress and ongoing debates. Blood Rev. 2008;22(1):33-52.

2. Kaplan C. Foetal and neonatal alloimmune thrombocytopaenia. Orphanet J Rare Dis. 2006;1:39.

3. Blanchette VS, Chen L, de Friedberg ZS, Hogan VA, Trudel E, Decary F. Alloimmunization to the PlA1 platelet antigen: results of a prospective study. $\mathrm{BrJ}$ Haematol. 1990;74(2):209-215.

4. Dreyfus M, Kaplan C, Verdy E, Schlegel N, DurandZaleski I, Tchernia G. Frequency of immune thrombocytopenia in newborns: a prospective study. Immune Thrombocytopenia Working Group. Blood. 1997;89(12):4402-4406.

5. Herman JH, Jumbelic MI, Ancona RJ, Kickler TS. In utero cerebral hemorrhage in alloimmune thrombocytopenia. Am J Pediatr Hematol Oncol. 1986; 8(4):312-317.

6. Weiner E, et al. Direct fetal administration of immunoglobulins: another disappointing therapy in alloimmune thrombocytopenia. Fetal Diagn Ther. 1994;9(3):159-164.

7. Gaddipati S, Berkowitz RL, Lembet AA, Lapinski R, McFarland JG, Bussel JB. Initial fetal platelet counts predict the response to intravenous gammaglobulin therapy in fetuses that are affected by PLA1 incompatibility. Am J Obstet Gynecol. 2001; 185(4):976-980.

8. Bussel JB, Zabusky MR, Berkowitz RL, McFarland JG. Fetal alloimmune thrombocytopenia. $N$ Engl J Med. 1997;337(1):22-26.

9. Bertrand G, Drame M, Martageix C, Kaplan C. Prediction of the fetal status in non-invasive management of alloimmune thrombocytopenia. Blood. 2011;117(11):3209-3213.

10. Mueller-Eckhardt C, et al. 348 cases of suspected neonatal alloimmune thrombocytopenia. Lancet. 1989;1(8634):363-366.

11. Murphy MF, Hambley H, Nicolaides K, Waters AH Severe fetomaternal alloimmune thrombocyto- penia presenting with fetal hydrocephalus. Prenat Diagn. 1996;16(12):1152-1155.

12. Ghevaert C, et al. Management and outcome of 200 cases of fetomaternal alloimmune thrombocytopenia. Transfusion. 2007;47(5):901-910.

13. Kjeldsen-Kragh J, et al. A screening and intervention program aimed to reduce mortality and serious morbidity associated with severe neonatal alloimmune thrombocytopenia. Blood. 2007; 110(3):833-839.

14. Brass LF, Zhu L, Stalker TJ. Minding the gaps to promote thrombus growth and stability. J Clin Invest. 2005;115(12):3385-3392.

15. Jackson SP. The growing complexity of platelet aggregation. Blood. 2007;109(12):5087-5095.

16. Ruggeri ZM. Mechanisms initiating platelet thrombus formation. Thromb Haemost. 1997;78(1):611-616.

17. Schoenwaelder SM, et al. Two distinct pathways regulate platelet phosphatidylserine exposure and procoagulant function. Blood. 2009;114(3):663-666. 
18. Monroe DM, Hoffman M, Roberts HR. Platelets and thrombin generation. Arterioscler Thromb Vasc Biol. 2002;22(9):1381-1389.

19. Heemskerk JW, Bevers EM, Lindhout T. Platelet activation and blood coagulation. Thromb Haemost. 2002;88(2):186-193.

20. Williamson LM, et al. The natural history of fetomaternal alloimmunization to the platelet-specific antigen HPA-1a (PlA1, Zwa) as determined by antenatal screening. Blood. 1998;92(7):2280-2287.

21. Kroll H, Kiefel V, Santoso S. Clinical aspects and typing of platelet alloantigens. Vox Sang. 1998; 74(suppl 2):345-354.

22. Bizzaro N, Dianese G. Neonatal alloimmune amegakaryocytosis. Case report. Vox Sang. 1988; 54(2):112-114

23. Goldman M, Trudel E, Richard L, Khalife S, Spurll GM. Neonatal alloimmune thrombocytopenia due to anti-HPA-2b (anti-Koa). Immunohematology. 2003;19(2):43-46.

24. Kroll H, Kiefel V, Muntean W, Mueller-Eckhardt C. Anti- $\mathrm{KO}^{\mathrm{a}}$ as the cause of neonatal alloimmune thrombocytopenia. Vox Sang. 1994;67(suppl):12.

25. Al-Sheikh IH, Khalifa M, Rahi A, Qadri MI, Al Abad $\mathrm{K}$. A rare case of neonatal alloimmune thrombocytopenia due to ANTI-HPA-2b. Ann Saudi Med. 1998; 18(6):547-549.

26. Grenet P, Dausset J, Dugas M, Petit D, Badoual J, Tangun Y. [Neonatal thrombopenic purpura with anti-Ko-a feto-maternal isoimmunization]. Arch Fr Pediatr. 1965;22(10):1165-1174.

27. Davoren A, Curtis BR, Aster RH, McFarland JG. Human platelet antigen-specific alloantibodies implicated in 1162 cases of neonatal alloimmune thrombocytopenia. Transfusion. 2004;44(8):1220-1225.

28. Cines DB, Blanchette VS. Immune thrombocytopenic purpura. N Engl J Med. 2002;346(13):995-1008.

29. McMillan R. Antiplatelet antibodies in chronic immune thrombocytopenia and their role in platelet destruction and defective platelet production. Hematol Oncol Clin North Am. 2009;23(6):1163-1175.

30. He R, Reid DM, Jones CE, Shulman NR. Spectrum of Ig classes, specificities, and titers of serum antiglycoproteins in chronic idiopathic thrombocytopenic purpura. Blood. 1994;83(4):1024-1032.

31. Bergmeier W, Rackebrandt K, Schroder W, Zirngibl H, Nieswandt B. Structural and functional characterization of the mouse von Willebrand factor receptor GPIb-IX with novel monoclonal antibodies Blood. 2000;95(3):886-893.

32. Kanaji T, Russell S, Ware J. Amelioration of the macrothrombocytopenia associated with the murine Bernard-Soulier syndrome. Blood. 2002; 100(6):2102-2107.

33. Bergmeier W, et al. The role of platelet adhesion receptor GPIbalpha far exceeds that of its main ligand, von Willebrand factor, in arterial thrombosis. Proc Natl Acad Sci US A. 2006;103(45):16900-16905.

34. Ni H, et al. A novel murine model of fetal and neonatal alloimmune thrombocytopenia: response to intravenous IgG therapy. Blood. 2006;107(7):2976-2983.

35. Chen P, et al. Animal model of fetal and neonatal immune thrombocytopenia: role of neonatal $\mathrm{Fc}$ receptor in the pathogenesis and therapy. Blood.2010; 116(18):3660-3668.

36. Sarig G, Vidergor G, Brenner B. Assessment and management of high-risk pregnancies in women with thrombophilia. Blood Rev. 2009;23(4):143-147.

37. Tong MH, Jiang H, Liu P, Lawson JA, Brass LF, Song WC. Spontaneous fetal loss caused by placental thrombosis in estrogen sulfotransferase-deficient mice. Nat Med. 2005;11(2):153-159.

38. Redecha P, van Rooijen N, Torry D, Girardi G. Pravastatin prevents miscarriages in mice: role of tissue factor in placental and fetal injury. Blood. 2009;113(17):4101-4109.

39. Olsson A, Andersson PO, Tengborn L, Wadenvik H.
Serum from patients with chronic idiopathic thrombocytopenic purpura frequently affect the platelet function. Thromb Res. 2002;107(3-4):135-139.

40. Yanabu M, et al. Influences of antiplatelet autoantibodies on platelet function in immune thrombocytopenic purpura. Eur J Haematol. 1991; 46(2):101-106

41. Matsubayashi H, Weidner J, Miraglia CC, McIntyre JA. Platelet membrane early activation markers during prolonged storage. Thromb Res. 1999;93(4):151-160.

42. Zarpellon A, et al. Binding of alpha-thrombin to surface-anchored platelet glycoprotein Ib(alpha) sulfotyrosines through a two-site mechanism involving exosite I. Proc Natl Acad Sci U S A. 2011; 108(21):8628-8633

43. Zampolli A, Roberts JR, Marchese P, Ruggeri ZM. Functional thrombin modulation in vivo by platelet glycoprotein Ib. J Thromb Haemost. 2009; 7(suppl 2):181.

44. Ni H, Papalia JM, Degen JL, Wagner DD. Control of thrombus embolization and fibronectin internalization by integrin alpha IIb beta 3 engagement of the fibrinogen gamma chain. Blood. 2003; 102(10):3609-3614

45. Reheman A, et al. Plasma fibronectin depletion enhances platelet aggregation and thrombus formation in mice lacking fibrinogen and von Willebrand factor. Blood. 2009;113(8):1809-1817.

46. Ni H, et al. Persistence of platelet thrombus formation in arterioles of mice lacking both von Willebrand factor and fibrinogen. J Clin Invest. 2000; 106(3):385-392.

47. Nicolini $U$, et al. Continuing controversy in alloimmune thrombocytopenia: fetal hyperimmunoglobulinemia fails to prevent thrombocytopenia. Am J Obstet Gynecol. 1990;163(4 pt 1):1144-1146.

48. Webster ML, et al. Relative efficacy of intravenous immunoglobulin $\mathrm{G}$ in ameliorating thrombocytopenia induced by antiplatelet GPIIbIIIa versus GPIbalpha antibodies. Blood. 2006;108(3):943-946.

49. Go RS, Johnston KL, Bruden KC. The association between platelet autoantibody specificity and response to intravenous immunoglobulin $\mathrm{G}$ in the treatment of patients with immune thrombocytopenia. Haematologica. 2007;92(2):283-284.

50. Ghetie V, Ward ES. Multiple roles for the major histocompatibility complex class I- related receptor FcRn. Annu Rev Immunol. 2000;18:739-766.

51. Roopenian DC, et al. The MHC class I-like IgG receptor controls perinatal IgG transport, IgG homeostasis, and fate of IgG-Fc-coupled drugs. J Immunol. 2003;170(7):3528-3533.

52. Firan M, et al. The MHC class I-related receptor, $\mathrm{FcRn}$, plays an essential role in the maternofetal transfer of gamma-globulin in humans. Int Immunol. 2001;13(8):993-1002.

53. Lens D, et al. Association between recurrent pregnancy loss and prothrombotic gene polymorphisms. J Thromb Haemost. 2003;1(suppl 1):P0951.

54. Hickstein H, Barz D, Kulz T, Korten G, Muller $\mathrm{H}$, Schmidt R. Protein A immunoadsorption in a pregnant woman with habitual abortion. Transfus Apher Sci. 2002;27(3):259-261.

55. Peng TC, Kickler TS, Bell WR, Haller E. Obstetric complications in a patient with Bernard-Soulier syndrome. Am J Obstet Gynecol. 1991;165(2):425-426.

56. Fujimori K, Ohto H, Honda S, Sato A. Antepartum diagnosis of fetal intracranial hemorrhage due to maternal Bernard-Soulier syndrome. Obstet Gynecol. 1999;94(5 pt 2):817-819.

57. Peitsidis P, Datta T, Pafilis I, Otomewo O, Tuddenham EG, Kadir RA. Bernard Soulier syndrome in pregnancy: a systematic review. Haemophilia. 2010; 16(4):584-591.

58. Woodrow JC, Finn R. Transplacental haemorrhage. Br J Haematol. 1966;12(3):297-309.
59. Bowman JM, Pollock JM, Penston LE. Fetomaternal transplacental hemorrhage during pregnancy and after delivery. Vox Sang. 1986;51(2):117-121.

60. Kumpel BM, Sibley K, Jackson DJ, White G, Soothill $\mathrm{PW}$. Ultrastructural localization of glycoprotein IIIa (GPIIIa, beta 3 integrin) on placental syncytiotrophoblast microvilli: implications for platelet alloimmunization during pregnancy. Transfusion. 2008; 48(10):2077-2086.

61. Kumpel B, et al. Phenotype and mRNA expression of syncytiotrophoblast microparticles isolated from human placenta. Ann N Y Acad Sci. 2008; 1137:144-147.

62. Konkle BA, Shapiro SS, Asch AS, Nachman RL. Cytokine-enhanced expression of glycoprotein Ib alpha in human endothelium. J Biol Chem. 1990; 265(32):19833-19838.

63. Rajagopalan V, Essex DW, Shapiro SS, Konkle BA. Tumor necrosis factor-alpha modulation of glycoprotein Ib alpha expression in human endothelial and erythroleukemia cells. Blood. 1992; 80(1):153-161.

64. Wu G, et al. Human endothelial cells in culture and in vivo express on their surface all four components of the glycoprotein Ib/IX/V complex. Blood. 1997;90(7):2660-2669.

65. Everett C. Incidence and outcome of bleeding before the 20th week of pregnancy: prospective study from general practice. BMJ. 1997;315(7099):32-34.

66. Wilcox AJ, et al. Incidence of early loss of pregnancy. N Engl J Med. 1988;319(4):189-194.

67. Schallmoser K, et al. The Fc gammaRIIa polymorphism R/H131, autoantibodies against the platelet receptors GPIb alpha and Fc gammaRIIa and a risk for thromboembolism in lupus anticoagulant patients. Thromb Haemost. 2005;93(3):544-548.

68. Isermann B, et al. The thrombomodulin-protein $\mathrm{C}$ system is essential for the maintenance of pregnancy. Nat Med. 2003;9(3):331-337.

69. Vanhoorelbeke K, Ulrichts H, Van de Walle G, Fontayne A, Deckmyn H. Inhibition of platelet glycoprotein $\mathrm{Ib}$ and its antithrombotic potential. Curr Pharm Des. 2007;13(26):2684-2697.

70. Aledort LM, Hayward CP, Chen MG, Nichol JL, Bussel J. Prospective screening of 205 patients with ITP, including diagnosis, serological markers, and the relationship between platelet counts, endogenous thrombopoietin, and circulating antithrombopoietin antibodies. Am J Hematol. 2004; 76(3):205-213

71. Sarpatwari A, et al. Thromboembolic events among adult patients with primary immune thrombocytopenia in the United Kingdom General Practice Research Database. Haematologica. 2010;95(7):1167-1175.

72. Thachil J, Callaghan T, Martlew V. Thromboembolic events are not uncommon in patients with immune thrombocytopenia. Br J Haematol. 2010;150(4):496-497.

73. Kanhai $\mathrm{HH}$, et al. Management of alloimmune thrombocytopenia. Vox Sang. 2007;93(4):370-385.

74. Ware J, Russell S, Ruggeri ZM. Generation and rescue of a murine model of platelet dysfunction: the Bernard-Soulier syndrome. Proc Natl Acad Sci U S A. 2000;97(6):2803-2808.

75. Hodivala-Dilke KM, et al. Beta3-integrin-deficient mice are a model for Glanzmann thrombasthenia showing placental defects and reduced survival. J Clin Invest. 1999;103(2):229-238.

76. Chang $M$, et al. Immune thrombocytopenic purpura (ITP) plasma and purified ITP monoclonal autoantibodies inhibit megakaryocytopoiesis in vitro. Blood. 2003;102(3):887-895.

77. Cosemans JM, et al. Key role of glycoprotein Ib/ V/IX and von Willebrand factor in platelet activation-dependent fibrin formation at low shear flow. Blood. 2011;117(2):651-660. 